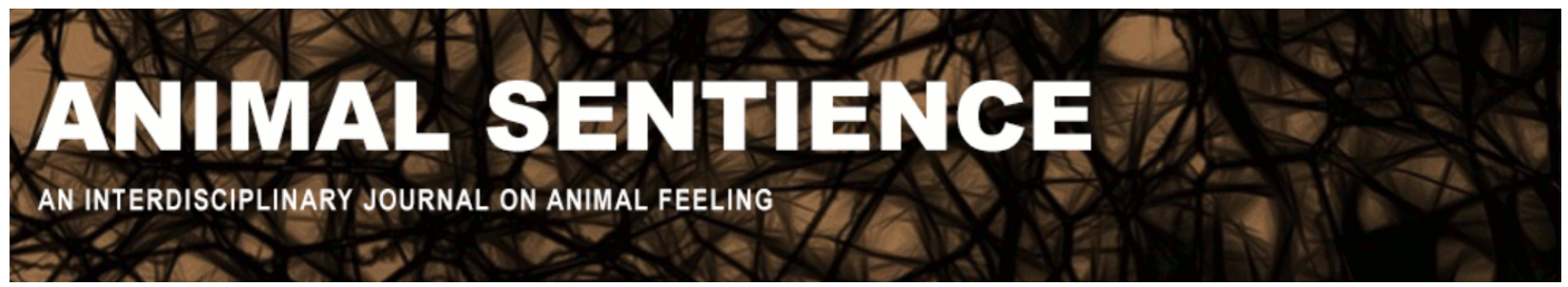

Birch, Jonathan (2017) Refining the precautionary framework. Animal Sentience 16(20)

DOI: $10.51291 / 2377-7478.1279$

Date of submission: $2017-12-20$

Date of acceptance: 2017-12-22

(c) (†)

This article has appeared in the journal Animal

Sentience, a peer-reviewed journal on animal

cognition and feeling. It has been made open access,

free for all, by WellBeing International and deposited

in the WBI Studies Repository. For more information,

please contact

wbisr-info@wellbeingintl.org.

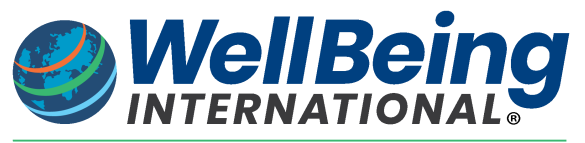

SOLUTIONS FOR PEOPLE, ANIMALS AND ENVIRONMENT 


\title{
Refining the precautionary framework
}

Response to Commentary on Birch on Precautionary Principle

\author{
Jonathan Birch \\ Department of Philosophy, Logic and Scientific Method \\ London School of Economics and Political Science
}

\begin{abstract}
Most of the commentators so far agree that the precautionary principle can be usefully applied to the question of animal sentience. I consider various ways of refining my proposals in light of the suggestions. I amend BAR to implement C. Brown's suggestion that the scope of animal welfare law should be extensible by phylogenetic inference from orders in which credible indicators of sentience are found. In response to C. Brown, Mallatt, and Woodruff, I amend ACT to allow that a single credible indicator may sometimes call for urgent further investigation rather than immediate protection. In response to Paez, I amend ACT to clarify that cost-effective measures to safeguard the welfare of animals that satisfy BAR should be included in any legislation relevant to their treatment in any domain of human activity. I consider and decline other suggestions, including Browning's suggestion that BAR should admit anecdotal evidence. I resist the charges that my proposals yield inconsistent advice or amount to "fiddling while Rome burns." I argue that my proposals support the inclusion of decapod crustaceans in animal welfare law but do not (contra Reber) support the inclusion of microbes.
\end{abstract}

Jonathan Birch is Assistant Professor at the London School of Economics and Political Science, specializing in the philosophy of biology. His book The Philosophy of Social Evolution was published by Oxford University Press in 2017. personal.lse.ac.uk/birchj1

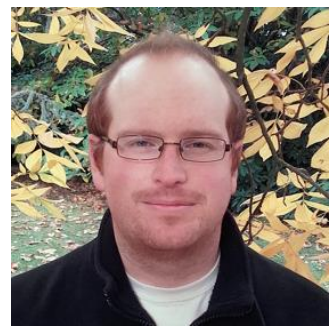

I thank all the commentators for engaging so carefully and constructively with my target article on animal sentience and the precautionary principle (Birch 2017a). Indeed, I am very surprised at the extent to which the commentary has been not only constructive, but also sympathetic. As Section 5 of the target article makes clear, there are influential voices who would entirely reject any application of the precautionary principle in this area - but these voices are currently absent from the discussion. Let me be clear that I welcome their involvement in the debate, if they want to join. In the meantime, I will respond to the many insightful points raised by the commentaries, most of which are in agreement with the fundamental point that the precautionary principle can be usefully applied to the question of animal sentience.

I have organized my responses by theme. Sections 1 to 4 focus on epistemic questions, discussing whether my proposed evidential bar for attributing sentience has been set too low (Section 1) or too high (Section 2), whether the order is the appropriate taxonomic grain of 
analysis (Section 3), and how lists of "credible indicators" should be developed (Section 4). Sections 5 and 6 turn to practical questions, elaborating on what it means to bring an animal "within the scope" of animal protection law (Section 5) and confronting the objection that the precautionary principle yields inconsistent advice (Section 6). Section 7 discusses the rather abstract (but interesting) question of how the precautionary principle relates to utilitarianism. Sections 8 to 10 consider particular cases raised by the commentaries: the decapod crustaceans (Section 8), other arthropods (Section 9), and unicellular eukaryotes (Section 10).

Section 11 confronts the objection that the entire project of building frameworks for enshrining sentience in animal welfare law is "fiddling while Rome burns," because it does nothing to address the main causes of animal suffering. This objection must be confronted, of course, but I hope readers won't mind if I postpone discussion of it until after the more specific issues raised by the commentaries have been dealt with. Finally, Section 12 reviews my amended proposals and invites further commentary.

\section{Is the BAR too low?}

Many commentaries focus on BAR, my proposal as to what an intentionally low burden of proof for animal sentience should require in practice. Four commentators argue that the proposed evidential bar is too permissive in some respects.

\subsection{More than one credible indicator?}

C. Brown, Mallatt, and Woodruff call for more credible indicators: Brown and Mallatt call for at least two rather than one, to ensure that there are at least two independent lines of evidence for sentience, whereas Woodruff calls for "substantially" more than one. Decapod crustaceans would still clear the Brown/Mallatt bar, if one counts both motivational tradeoffs (Appel and Elwood 2009; Elwood and Appel 2009) and conditioned place preference (Magee and Elwood 2013) as credible indicators, but it would be a higher bar for currently under-studied taxa to clear.

In response, I should note that requiring "at least one" credible indicator is not as lax a requirement as it may initially seem. This is because the list of credible indicators should be carefully regulated to ensure only indicators with a strong theoretical link to sentience are admitted (see Section 4 below). For example, possession of nociceptors is not a credible indicator by itself: there must be evidence that nociceptive information is being centrally integrated with information from other sources. This is why motivational trade-offs, where at least one of the factors in the trade-off is detected by nociception, are a good indicator: they indicate that the animal is integrating information about a noxious stimulus with information about other things it values and disvalues. Having one indicator of sentience in this relatively demanding sense is more of an achievement than having two indicators of a more minimal type.

This does not entirely address the worry about relying on a single experiment or type of experiment. The underlying concern, I take it, is that this type of experiment may subsequently be found to be methodologically suspect, undermining the case for including the relevant order within the scope of animal welfare law. For example (as I noted in the target article, and as Woodruff also notes), the experiments from the late 1980s and early 1990s (Lozada et al. 1988; Bergamo et al. 1992) that appeared to show opiate-induced 
analgaesia in Chasmagnathus granulatus and Carcinus mediterraneus could not be replicated by Barr and Elwood (2011) in Carcinus maenas. As Barr and Elwood (2011) note, an alternative explanation for the earlier results is that opiates merely induced "a temporary inability to move" (p. 343).

But we should take a step back here to consider the wider context. The European Food Standards Agency's Animal Health and Welfare Panel (2005) used the earlier experiments as a basis for recommending the extension of animal welfare legislation to decapods. The recommendation was not implemented - and indeed, the experiments were subsequently called into question. At the same time, however, and by the same lab, new evidence of sentience (as noted above) was collected - yet there has so far been no policy response to this evidence, in either the European Union (EU) or the UK. We see here a systemic problem: the tentative and fallible nature of the present evidence (and it is always tentative and fallible) is used as a reason to kick the issue of decapod welfare into the long grass, without any serious attempt to respond to new evidence when it appears.

What, then, should happen in a situation in which, at the time of an important policy decision, there is tentative, fallible evidence of one credible indicator of sentience in a given order, but further work is needed before we have two? Is it reasonable to omit the order from the scope of animal welfare legislation, knowing that it could be decades before the issue is revisited? It is not: the welfare costs of that decades-long wait are potentially severe. The appropriate response is either to include the order in question immediately as a precaution or, failing that, to give high funding priority to the search for further indicators of sentience in that order and commit to revisit the issue in the short-term. Neither has happened in the case of decapods in the EU or UK, and this is a problem (for more on decapods, see Section 8).

In general, it seems to me that tentative, fallible evidence of one credible indicator is enough to warrant action of some kind. The action may take the form of bringing the order within the scope of animal welfare law immediately, or it may take the form of commissioning further research into sentience in that order as a matter of priority (see Section 5 for the incorporation of this into ACT). But there is no justification for continuing inaction in the presence of both credible evidence of sentience and knowledge that, if the animals in question are sentient, their treatment is severely under-regulated.

\section{2. "But AI can do that!"}

Adamo raises an interesting objection: some forms of learning often taken to be indicative of sentience in animals can also be achieved by artificial intelligence (AI). Adamo (2016) gives the example of the "MoNETA" (Modular Neural Exploring Travelling Agent), an artificial neural network developed in 2012 containing 32 million "neurons" and 13 billion connections (Ames et al. 2012). Ames et al. (2012) report that MoNETA, when put in control of a small robotic rat, learned how to complete the Morris water navigation task, a task in which a rat must find its way to a raised platform in a water maze. It is not clear how far the project has advanced since 2012 .

Adamo seems to take it for granted that AI is always non-sentient. I suppose I am less certain than Adamo that this is the case. I think it is quite possible that by the end of the century there will be AI systems with human-level intelligence, and that the sentience of these systems will be widely accepted (Bostrom 2014). This will raise difficult ethical, social, political and legal issues in its own right (Basl 2013; Bostrom and Yudkowsky 2014). But now think about the steps along the way to human-level AI. It seems plausible that the path will 
involve a sequence of increasingly intelligent artificial minds that are also sentient - but, almost inevitably, their sentience will not initially be recognized or taken seriously.

Could we be at this stage, or close to it, already? Superficially, a deep neural network with 32 million neurons appears more complex than a lobster's nervous system of 100,000 neurons. Such comparisons are crude, because the "neurons" in AI algorithms are not biological neurons, and they lack the rich functional flexibility of biological neurons. Nevertheless, are we sure that such algorithms cannot be sentient? Are we sure there are no ethical limits on what we can do to them? Speaking for myself, I am not entirely sure. I am not proposing that we extend the Animal Sentience Precautionary Principle to AI sentience that is a different debate for another occasion. My claim is rather that sophisticated learning in AI should not be taken as proof that such learning is possible without sentience.

Of course, the case of a deep neural network learning about its environment should be distinguished from cases in which a robot is simply programmed to display pain-like behaviour in response to stimuli. In these cases, the behaviour is not a credible indicator of sentience, because information about noxious stimuli is not being integrated with information about other aspects of the situation to enable flexible decision-making (see Section 4).

On one important point I do agree with Adamo: animal sentience researchers and AI researchers have much to learn from each other. Both fields have a shared interest in nonhuman sentience, and both fields must confront the questions of how to detect it, how to understand it, and what to do about it.

\section{Is the BAR too high?}

The critics arguing for a raising of BAR are counterbalanced by four commentators arguing that BAR is in some respects too demanding. C. Brown features again here, because he thinks BAR, while too permissive in some respects, is also too demanding in others (Section 2.3).

\subsection{A presumption of sentience?}

Leadbeater challenges my claim that "there cannot be a default presumption of sentience in all cases," arguing that there should be a default presumption of sentience for all animals. Leadbeater further suggests that "a high evidential bar to indicate nonsentience could substitute for Birch's low evidential bar suggesting sentience." I take the proposal to be that, by default, all animals should be included in the scope of animal welfare law, including nematodes and sponges - and those who want a particular species excluded should be forced to provide strong evidence of the absence of sentience in that species.

I suspect that such a framework would not work very well in practice, because there are no clear standards for evidence of the absence of sentience. If the absence of credible indicators of sentience is enough, then we are more or less back to BAR. But if a positive indication of non-sentience is required, then we have to say something about what forms this could take - and I am not at all clear about this.

A related concern is that, in the absence of a clear approach to managing exceptions, a presumption of universal animal sentience would be toothless. An example is the EU's Lisbon Treaty, an article which states "the Union and the Member States shall, since animals are sentient beings, pay full regard to the welfare requirements of animals" (European Union 2007). This is most naturally read as a claim about all animals, not just some. But the reality 
is that European law continues to apply only to some animals, with the scope of particular directives being decided on an ad hoc basis. What is needed is a clear framework for setting the proper scope of legislative concern - and this is what my proposals aim to provide.

\subsection{Anecdotal and other weak evidence}

Browning argues that anecdotal evidence should be admitted for the purposes of BAR when obtained from multiple reliable sources. Browning gives several examples of behaviours, such as imitation in orangutans, that have come to be accepted only on the basis of repeated anecdotal observations. She further argues that cephalopods - protected in scientific research in the EU by the 2010 directive on the protection of animals used for scientific purposes (European Union 2010) - could have been protected far sooner if anecdotal evidence about their capabilities had been taken seriously. Browning makes a persuasive case, and to explain why I ultimately reject it, I will need to say more about my motivation for excluding anecdotal evidence. My motivation is not a general mistrust of such evidence, but a more specific concern about what happens when it is relied upon in policy-making contexts.

It goes without saying that whoever is asked to advise on the scope of animal welfare legislation will bring their particular values, priorities and interests to the process. For animal welfare scientists, it is the consequences for animals that are most salient; for representatives of the bioscience sector, it is the consequences for research, and in particular the potential medical breakthroughs that may be foregone if research becomes more difficult; and for representatives of the food industry, it is the consequences for prices and employment in their sector.

As a consequence of these divergent values, priorities and interests, experts on different sides are naturally led to doubt one another's reliability. We see this dynamic at work in my focal case in Section 5 of the target article: the debate over whether decapods should have been included in the 2010 EU directive. The AHAW (2005) report overstated the case for decapod sentience, given the evidence available in 2005 (prior to Elwood's recent work). The panel described decapods as Category 1 animals, where Category 1 implies that "The scientific evidence clearly indicates that those groups of animals are able to experience pain and distress." This overstatement was unsurprising, given the panel's natural concern for protecting decapod welfare - but, unfortunately, it allowed others to cast doubt on the report's reliability. The UK Bioscience Sector (2009) replied in blunt terms:

"The report of the Scientific Committee of the European Food Standards Agency (EFSA) does not provide robust scientific evidence to support such an extension. Extensive studies have not produced scientific evidence that decapods perceive pain and might 'suffer' during scientific procedures." (p. 18)

This was doubly misleading, since there had not at that time been "extensive studies" of decapod sentience (indeed, it is still the case that the topic is under-explored), and the most recent studies available in May 2009 (e.g., Barr et al. 2008; Appel and Elwood 2009) had in fact yielded scientific evidence of sentience. But this too is unsurprising, given the bioscience sector's obvious interest in minimizing regulation of scientific research.

We thus see how, in the absence of an agreed framework for settling such questions, conflicting values, priorities and interests lead to overstatements, distortions and mutual mistrust. I do not intend to apportion blame here or declare one side worse than the other. 
What should be clear is that there is a need for a framework that can be common ground in debates of this kind. A key desideratum of such a framework is that it set an objective and transparent standard for reliable evidence to which all sides can agree, despite differences in their values, priorities and interests.

This is why anecdotes must be deemed inadmissible. I agree that, in non-adversarial contexts in which we aim only to understand animal behaviour, an accumulation of anecdotes from sources whose reliability is not in doubt can be a useful source of evidence. But in the process of making animal welfare law, it is inevitable that the reliability of the sources will be called into doubt - the source will always be suspected by the other side of allowing their values to distort their testimony - and so there must be an objective standard of reliability that can be called upon to answer these doubts. There is no objective standard of reliability for anecdotes.

Now, one may well question whether statistical significance is really up to the job of providing an objective standard of reliability (Irvine does in fact question this in her commentary). Recent replication crises across the sciences, and in psychology in particular, have raised awareness of the perils of "p-hacking" and publication bias. It may well be that normal scientific standards will change as a result: for example, a number of psychologists have recently proposed raising the $\mathrm{p}$ bar by lowering the standard $\mathrm{p}$-value to $\mathrm{p}=0.005$ (Benjamin et al. 2017). My view is that, wherever normal scientific standards go, BAR should follow. If normal scientific standards become more stringent, then so should BAR. If that means that some experimental results, such as Elwood's (which would not meet the $p=0.005$ threshold), fall short of the new, more stringent standards, then so be it: the experiments will have to be repeated with larger samples.

This may sound rather conservative - but I think it is the only way to ensure that extensions to the scope of animal welfare law are not successfully blocked by the powerful forces that invariably resist them.

Similar considerations apply to R. Brown's suggestion that, in the absence of statistically significant evidence, we should count "multiple, weak, but convergent, lines of evidence" as admissible for the purposes of BAR. I agree that there are many species for which all we have is "limited, poor-quality evidence." The problem is that, if BAR were to include a clause admitting limited, poor-quality evidence, it would no longer set an objective and transparent standard for reliable evidence. For example, there is some very limited, very poor-quality evidence of sentience in some unicellular eukaryotes (see Section 10). How much better than this does the evidence have to be before a policy response should be triggered? BAR provides a clear answer: there must be at least one statistically significant experimental result showing at least one credible indicator (where credible indicators are defined with reference to a published list; see Section 4). If we excise this element of BAR, it will no longer provide a clear answer.

The commentaries by Browning and R. Brown highlight that the appropriate evidential bar depends on the use to which the framework is to be put. I want a commonground framework for setting the scope of animal welfare law: one that recognizes the need to err on the side of caution while also setting an evidential bar that is clear enough, precise enough and demanding enough to command widespread support. For other purposes, such as advising animal welfare organizations where to focus their resources, or advising funding bodies on where additional research is most urgently needed, a different burden of proof that recognizes some forms of anecdotal evidence might be useful. 


\subsection{Extension by phylogenetic inference}

One suggestion I fully agree with is C. Brown's proposal that we should be able to attribute sentience to orders for which we do not have any direct experimental evidence, if we have evidence of sentience in enough sufficiently related orders to make a phylogenetic inference. For example, if we have sufficient evidence of sentience in the Cypriniformes and Salmoniformes, and if considerations of cladistic parsimony make a separate origin for sentience in the two orders unlikely, we should infer that the common ancestor of all Clupeocephala was sentient - and this should in turn lead us to conclude that the evidence of sentience is sufficient in all Clupeocephala. There remains the question of how exactly to incorporate this consideration in the formulation of BAR. I suggest the following:

\section{BAR (v1.1):}

(a) For the purposes of formulating animal protection legislation, there is sufficient evidence that animals of a particular order $\left(\mathrm{O}_{1}\right)$ are sentient if there is statistically significant evidence, obtained by experiments that meet normal scientific standards, of the presence of at least one credible indicator of sentience in at least one species of that order.

(b) If sufficient evidence by the lights of condition (a) has been obtained for two orders $\mathrm{O}_{1}$ and $\mathrm{O}_{2}$, and if normal methods of phylogenetic inference indicate that, conditional on the presence of sentience in orders $\mathrm{O}_{1}$ and $\mathrm{O}_{2}$, animals of a third order $\mathrm{O}_{3}$ are also likely to be sentient, then there is sufficient evidence that animals of the order $\mathrm{O}_{3}$ are sentient.

I say "normal methods" here to allow (as in condition a) that a variety of different methods may be appropriate and that methods may change over time. The point is simply that we should not rely on intuitions, hunches or anecdotes, nor should we employ deliberately lax methods that would not be used for phylogenetic inference on other traits.

\section{Is the order the right grain of analysis?}

As Stauffer and Mallatt point out, my reliance on the concept of the Linnaean category of the order in formulating BAR looks outdated at first sight. Linnaean higher taxa have no role in phylogenetic taxonomy, which is "rank free" (De Queiroz and Gauthier 1992; Mishler 1999; though cf. Benton 2001). From a phylogenetic point of view, taxonomic ranks such as the order are artificial constructs, not natural kinds.

The obvious alternative proposal is to revert to "species" and rely on clause (b) in BAR v1.1 to extend the scope of legislative concern to larger clades. But the problem here is this: what happens when we have evidence of sentience in a single species, and no evidence concerning any other phylogenetically nearby species? The alternative proposal says: protect only the single species for which you have evidence. My proposal says: paint with a deliberately broad brush — protect the entire order.

It seems to me that my proposal is more in keeping with the imperative to err on the side of caution. Despite being an artificial construct, I think the concept of an order turns out to be a pragmatically useful one in this context. It groups animals at a deliberately coarse grain of analysis, which is what we want. It is also well-known, easy to understand and fairly unambiguous. It may be more useful for animal welfare legislation than it is for scientific taxonomy - but it is by now a well-known point that different taxonomic concepts are appropriate for different purposes (Dupre 1981; Kitcher 1984). 


\section{Towards a more comprehensive list of credible indicators}

BAR is of no practical use without an agreed list of credible indicators of sentience. I find Feinberg and Mallatt's (2016) list a useful starting point. Under behavioural indicators, they include operant conditioning, trade-off behaviour, frustration behaviour or negative contrast (i.e., "degraded behaviour after a learned reward unexpectedly stops"), self-delivery of analgesics when injured and conditioned place preference (p. 153). Equally helpful is Feinberg and Mallatt's list of behaviours not indicative of pain: the mere existence of nociceptors, classical conditioning (which can be achieved by the spinal cord), reflex responses and innate motor programs (p. 152). Stauffer argues that self-delivery of analgesics, motivational trade-offs and conditioned place preference are not necessarily indicative of pain. The first might be mere addiction (although, to make this less likely, we should require that the self-delivery is conditional on injury), whereas the second and third might be due to the animal disfavouring a particular stimulus without finding it painful. He also suggests that natural selection provides a better explanation of these behaviours; but natural selection and sentience are not rivals: the former is an ultimate cause, the latter a proximate one (in the sense of Mayr 1961).

Of course, all these behaviours might conceivably occur without pain, particularly if one insists that a state counts as pain only if it feels like human pain. What is harder to dispute is that these behaviours require the integration, by the central nervous system, of information about past or current injury with information about the animal's other needs or aspects of its environment, in such a way as to enable a flexible response to the situation. I suggest that this is the mark of a credible indicator of sentience, because it aligns with a plausible picture of the function of aversive feelings such as pain and discomfort for animals that feel them. Aversive feelings are guides to decision-making. To make flexible decisions, animals need to be able to weigh the seriousness of an injury against other things they need: sometimes fleeing is the right thing to do; sometimes carrying on as normal is the right thing to do; sometimes tending the injury is the right thing to do - it depends on the situation. Negative valence is the currency in which the need to stop, or the need to flee, is measured. When we find an animal making flexible decisions by integrating information about past or present injury with information about other aspects of its situation, that is a credible indicator of a negatively valenced (aversive) experience.

I call Feinberg and Mallatt's list a "starting point" because it is surely not comprehensive: it includes the credible indicators animal sentience researchers have so far thought to investigate, but not all possible such indicators. Mather's commentary highlights the need for a more comprehensive list and makes some helpful suggestions based on her work with cephalopods. I agree with Mather that although (in light of the "mark" proposed in the previous paragraph) the mere presence of nociceptors is not a credible indicator of sentience, the presence of connecting pathways linking peripheral nociceptors to integrative brain centres (Criterion 3 of Smith and Boyd's 1991 list) is a credible indicator. Similarly, although I do not think that the mere presence of opioid receptors should be counted as a credible indicator, the integration of an endogenous opioid system with mechanisms of learning and flexible decision making should count. The upshot is that the apparent distinction between neurofunctional and behavioural indicators is not as sharp as it may initially seem: the search for one type of indicator informs the search for the other. 


\section{Fleshing out ACT}

Paez highlights the need for more detail in ACT, my proposal as to what action is required when BAR is satisfied. He asks: which practices should animal welfare law aim to regulate? He raises the issue of wild animals: should we attempt to protect sentient animals in the wild, or not? My answer is that the treatment of any sentient animal in any domain of human activity should be regulated. We cannot regulate the treatment of wild animals to the extent that we regulate the treatment of farmed and captive animals, but we can prohibit practices (such as fox hunting) that are likely to cause poor welfare. This should extend to regulation of the culling of animals for veterinary or conservation reasons, which should be done humanely and only as a last resort.

Beyond that, I think detail about the material content of animal welfare legislation is best avoided in a framework such as this - a framework that aims only at fixing its scope. Once it is agreed that a previously excluded order should be brought within the scope of animal welfare law, there will always be a further debate to be had about whether existing law adequately covers the welfare needs of the animals in that order, or whether new law is required. But my framework is not intended to settle these debates, only to start them.

Clause (b) in the revised ACT below is intended to make this clear. Meanwhile, clause (c) introduces into the formulation of ACT the concession made in Section 1.1 to C. Brown, Mallatt, and Woodruff - the concession that borderline cases in which the presence of one credible indicator is disputed, or in which there is one credible indicator but not two, may call for urgent further research rather than immediate protection.

\section{ACT (v1.1):}

(a) The scope of animal protection legislation should include all orders of animals for which the evidence of sentience is sufficient, according to the standard of sufficiency outlined in BAR.

(b) When an order of animals is included in the scope of animal protection legislation, costeffective measures to safeguard the welfare of these animals should be included in any legislation relevant to their treatment in any domain of human activity, including food production, scientific research, conservation work and recreational pursuits.

(c) In cases in which it is disputed whether an order $\mathrm{O}_{1}$ satisfies BAR, or in which there is experimental evidence of one credible indicator of sentience in $\mathrm{O}_{1}$ but not evidence of two, it may be appropriate to commission further research into the question of sentience in $\mathrm{O}_{1}$ as a matter of high funding priority, and to commit to review the status of $\mathrm{O}_{1}$ after a short period of time. If no significant new evidence comes to light either for or against sentience, there should be a presumption in favour of protecting $0_{1}$.

\section{Inconsistency and proportionality}

Critics of the precautionary principle have long argued that it yields inconsistent advice. The basic argument is that any precaution creates new risks, leading it to be both mandated and prohibited by the precautionary principle (Sunstein 2005). Klein offers a version of this objection:

"There is a chance that decapods are sentient [...]. The PP says: avoid using them for research. Yet perhaps decapod research could help cure cancer, and thereby prevent untold harm to sentient humans. (A weak could is all that the PP demands.) The PP says full steam ahead." 
Part of the problem here is the assumption that there is one precautionary principle, applicable to all decisions. We should, I think, switch to talking about precautionary principles tailored to particular risks, of which ASPP is one example. My framework does not recommend banning research on decapods (it just says: bring them within the scope of animal welfare law), nor could it mandate such research - so I see no problem of inconsistency looming for my principle. There would be a problem if there were a credible risk that extending the scope of animal welfare law would create an environmental or public health catastrophe, because this would bring the recommendations of ASPP into conflict with other precautionary principles - but there is no such risk.

In general, these alleged problems of inconsistency are exaggerated. As Klein notes, Steel (2013) argues persuasively that such problems are avoided by requiring that any proposed precaution must pass a test of consistency (it is not prohibited by the same principle used to justify it) and efficiency or cost-effectiveness ("precautions aim to effectively minimize a target threat while keeping negative side effects to as minimal a level as possible"). Steel uses "proportionality" to refer to the combined requirements of consistency and efficiency. BAR and ACT are intended to achieve proportionality in Steel's sense.

\section{The precautionary principle and utilitarianism}

Ng argues that ASPP can be justified as a special case of a more general principle of expected net-welfare maximization, a version of utilitarianism. The basic idea is simple: the expected welfare consequences of treating a sentient animal as if it were non-sentient are far worse than the expected welfare consequences of treating a non-sentient animal as if it were sentient. Given this asymmetry of risk, the way to maximize expected welfare is to treat the animal in question as if it were sentient as soon as the probability of sentience exceeds a very low threshold (a threshold that depends on exactly how much worse it would be to incorrectly regard it as non-sentient). BAR can be interpreted in this light as a practical rule of thumb for adjudicating whether the probability of sentience meets this threshold.

I am sympathetic to the idea that ASPP, and other precautionary principles, can be justified on the grounds that they maximize expected welfare over the long run, and to the idea that expected welfare maximization should be the overarching goal of animal welfare science and policy (see Birch forthcoming). The commentary on Ng's own recent target article in this journal ( $\mathrm{Ng} \mathrm{2016)} \mathrm{contains} \mathrm{extensive} \mathrm{discussion} \mathrm{of} \mathrm{whether} \mathrm{welfare} \mathrm{maximization} \mathrm{is}$ an appropriate goal, and I won't discuss this issue further here (although see Section 11). However, I will note two qualifications regarding the relation between expected welfare maximization and ASPP.

First, I think one of the attractions of ASPP is that it does not presuppose any particular ethical framework (e.g., utilitarianism), but rather aims to capture a common-sense idea (i.e., give the animal the benefit of the doubt) that can be justified in various ways. As Ng observes, the utilitarian justification is clear enough. However, ASPP might also be justified in deontological (duty- or rights-based) terms, as a principle grounded in our duty to animals to protect them from unnecessary suffering. This general duty might plausibly be taken to ground a more specific duty to assign special priority to mitigating risks of serious negative 
welfare outcomes when they credibly arise, and my proposed framework can be interpreted as a way of fulfilling that duty.

The upshot is that one can endorse ASPP without endorsing any particular wider ethical view from which it may be derived. ASPP is intended to be a common-sense principle of broad appeal - not just a principle for utilitarians. Moreover, it is intended to be a principle of intermediate generality: a principle not so specific as to apply only to a single case or to a very circumscribed set of cases, nor so general as to say nothing more than "Maximize expected utility!" or "Avoid unnecessary suffering!" My sense is that a principle of this kind is what policy-makers, at least in the UK and EU, currently want and need.

Second, another attraction of ASPP is that it avoids concerns about the commensurability of different types of suffering and welfare - concerns that inevitably arise for an expected welfare maximization framework (e.g., Harnad 2016 on Ng 2016). An expected welfare maximization framework requires us to weigh (for example) the expected welfare benefits to decapod crustaceans of receiving basic legal protections against the expected welfare costs to humans, perhaps in the form of (i) higher costs for food producers, leading to fewer jobs and higher prices and (ii) more paperwork surrounding scientific research, leading to less research being done. I take these costs to be worth paying, but this is a qualitative judgement, not a judgement based on a quantitative calculation. As soon as one attempts a quantitative calculation of this sort, one runs into problems of commensurability: what exactly is the common currency in which decapod suffering and human well-being are to be measured? How much does a human have to benefit, and in what ways, to offset the suffering of a single crab? How does one even begin to enumerate and aggregate these effects?

ASPP, like other precautionary principles, provides a way of circumventing these concerns about commensurability, which can otherwise perpetually delay policy responses to developing threats (Steel 2013, 2014). It does so by setting a default evidential bar, and by saying: when this bar is cleared, act now, regardless of your concerns about paperwork or food prices. Precautionary principles thus offer a kind of "shortcut" decision procedure that appropriately applies in cases (such as climate change) when action must be taken quickly to mitigate a serious risk, but when a quantitative analysis of expected consequences would be subject to potentially endless arguments about the commensurability of qualitatively different costs and benefits.

\section{The case of decapod crustaceans}

I suggested in the target article that the decapod crustaceans were a good example when thinking about the use of precautionary reasoning in relation to animal sentience. As noted above (see Section 1.1), Elwood and colleagues have found evidence of motivational tradeoffs in hermit crabs (Appel and Elwood 2009; Elwood and Appel 2009) and of conditioned place avoidance in shore crabs (Magee and Elwood 2013). Although there is room for reasonable debate on this issue, a good case can be made that they satisfy BAR - yet they currently fall outside the scope of animal welfare legislation in the UK, EU, USA, and most other countries. My proposals therefore indicate that a change in the law may be justified in this case (see Birch 2017b).

An underlying assumption of the entire framework is that when sentient animals are not protected by animal welfare legislation, they are put at greatly increased risk of serious, 
negative welfare outcomes. In the case of decapods, the case can be easily made by pointing to practices widespread in the food and fishing industries such as live boiling, live carving, and de-clawing - practices that, if inflicted on a vertebrate, would violate even the most minimal animal welfare standards (Elwood 2012; Roth and Grimsbø 2016).

Carder presents a preliminary study of the welfare of lobsters in UK food outlets, focusing on restraints, stocking density, lighting and shelter. Conditions are far from optimal, with lobsters often housed in very high densities and never given access to shelter. This is a salutary reminder that, in the absence of legislative protection, animals can experience poor welfare even in public-facing settings such as supermarkets. Of course, we should also be concerned about what happens to these lobsters once they are bought - presumably, by customers with no training in the slaughter of lobsters and no access to specialist equipment. Less obviously, we should also be concerned about what happens to them earlier in the supply chain, where they are often held in storage facilities for long periods. It seems to me (and I imagine Carder would agree) a welfare scandal that these animals are sold live by supermarkets at all, independently of the question of whether their housing conditions are adequate.

\section{Other arthropods}

What of other arthropods? Both Adamo and Mallatt read me as denying the sentience of Drosophila fruit flies, but I do not - Drosophila appears in the target article only as an illustration of the severe consequences for scientific research of a presumption of universal sentience. If insects such as Drosophila are brought within the scope of animal welfare law, a very large amount of research would be subject to regulations from which it was previously exempt. So be it, if this is where the evidence leads (see the article by Klein and Barron 2016, and commentaries, for a discussion of the evidence). But we should be particularly mindful of the need to implement feasible, streamlined procedures for the reporting, evaluation and approval of projects, and to give careful consideration to the cost-effectiveness requirement.

\section{Sentient microbes?}

Reber suggests that there is good evidence for attributing sentience to unicellular organisms. On first reading, I took him to be arguing (like Leadbeater) for a presumption of universal sentience in the absence of sufficient evidence (see Section 2.1), but on a closer reading, it is apparent he believes microorganisms (but not plants) actually satisfy BAR.

Reber goes on to point out that this would leave the law in a difficult position, since protecting the welfare of sentient microbes would be unfeasible. He advocates a pragmatic approach on which the welfare benefits of regulating the treatment of a given species are weighed against the costs to humans. Curiously, Reber cites recreational fishing as an example in which the costs to humans might outweigh the benefits to animals, an idea I find unfathomable. He adds that "fish feel pain but it's far from obvious how to do anything to lessen it within the fishing industry" - but there are detailed reports on how it can be lessened (Mood 2010).

This is an illustration of how universal sentience, while initially sounding like good news for animal welfare, soon becomes a counsel of despair: if my own immune system daily slaughters billions of sentient bacteria, why worry about commercial fishing? If plants are 
sentient (a possibility rejected, admittedly, by Reber), could plant-based agriculture be even worse for sentient beings than meat production? This line of thought should be resisted not by casually dismissing the possibility of microbial or plant sentience, but by setting an evidential bar for admission into the scope of legislative concern and rigorously applying that bar.

So what is the evidence of sentience in microbes? Reber mentions the observations, by Jennings $(1902,1906)$, of a graded sequence of responses to a noxious stimulus in ciliates of the Stentor genus, reviewed (as part of a comprehensive review of "intelligent behaviour" in protozoa) by Trewavas (2014). Trewavas (2014) describes the response of Stentor to being blasted with a stream of carmine particles:

"The cell responded initially by bending the mouth to avoid these particles. The organism exercises choice. It repeated this action of bending several times if the initial bending failed. If the stream continued, the cilia reversed direction to drive the particles away. If this procedure continued to fail to stop the particles entering the mouth, the cell contracts into the tube. After a short time, the cell can re-emerge and try again to feed normally. If the carmine particle stream is continued, the contraction periods increase in length. Eventually, if the stream continues, then the Stentor cell exhibits violent contractions to break the adhesion of the foot and swims away." (p. 205)

The increasing length of the contraction periods is suggestive of avoidance learning, though I do not regard very limited forms of avoidance learning as credible indicators of sentience: to indicate sentience, they must involve the integration of information about a noxious stimulus with information about other aspects of the situation (see Section 4). Intriguingly, another stentor specialist, Tartar (1961), adds:

"From my own observations it appears that stentors from cultures which have recently been fed are more likely to persist in the feeding response and to give the graded response, as if bothered by the interruption of a good thing, whereas unfed animals are more likely to detach and swim away at once, as if the negative stimulus finally prodded them to "decide" to go in search for food." (pp. 20-21)

The latter remark is suggestive of a motivational trade-off: the stentor acts as if trading off the positive valence of the food against the negative valence of the carmine particles. However, this is not a statistically significant experimental result - it is just a report of anecdotal observations (cf. Section 2.2). Even if the trade-off exists, it would take further work to show that it results from information processing rather than from a mechanical effect, such as interference between the mechanisms of feeding and detachment. For these reasons, the remark should be read as a hypothesis rather than a result. The same can be said of Jennings's work in the early 1900s. A descriptive account of personal observations, though potentially a fruitful source of hypotheses, is not evidence of the right sort to satisfy BAR.

But suppose further investigation were to vindicate the observations of Jennings and Tartar. What then? If we found just one credible indicator of sentience (e.g., motivational trade-offs), the case would fall under clause (c) of ACT v1.1 (see Section 6), and further research should be funded as a matter of high priority. What if this research uncovered further credible indicators? We would face a difficult choice: remove the relevant indicators from the list of credible indicators of sentience - on the grounds that they turn out to be 
present in creatures without nervous systems - or give stentors a basic degree of legal protection. I'm not sure what my own response would be, and I don't think I need to prescribe one here. This is a debate that must be had if solid scientific evidence of credible indicators of sentience in organisms without nervous systems arises. At present, I take there to be no such evidence.

\title{
11. Fiddling while Rome burns
}

Marks objects that my target article is an exercise in "fiddling while Rome burns":

\begin{abstract}
"Animal ethics concerns a pressing, perhaps the most pressing ethical issue of our time: the immiseration and slaughter or extinction by human agency of sentient beings on an unprecedented scale. Much work, including of the mind, needs urgently to be done. But finetuning the treatment of confined or captured animals by the scientific investigation of sentience is not part of it, it seems to me."
\end{abstract}

There are three parts to this "big picture" concern. The first part is that I regard disputed cases of sentience - such as fish, arthropods and cephalopods - as genuinely difficult cases in need of further scientific investigation, when in reality it is (Marks contends) obvious from cursory observation of their behaviour that even clams and scallops are sentient. I don't think it is obvious, and I think the scientists who are trying to bring evidence to bear on these questions are doing valuable work.

The second part is that it is naïve to think policy can be made responsive to science in the way my proposals require, given the long history of policy-makers ignoring relevant science (as documented in the commentaries by Jones and Rollin) - and given the suffering that humans continue to inflict on mammals and birds, despite the wide acceptance of sentience in these taxa.

I am not as pessimistic as Marks, Jones, or Rollin on this score. These commentaries taken together present a bleak picture of US animal welfare policy, but I take the UK and EU contexts to be more favourable to my aims. The EU is committed to recognizing animal sentience via the Lisbon Treaty, and is also committed to the precautionary principle, but has no rules for applying the latter to the former. The UK government recently refused to incorporate the relevant article of the Lisbon Treaty into the EU Withdrawal Bill, but, after substantial criticism, published a statement committing to recognize animal sentience in UK law in some form (Gove 2017). My proposals are intended to help lawmakers in the EU and UK achieve their own stated aims. They clarify which animals should be recognized as sentient, and what steps should be taken to protect animals so recognized. Policymakers looking for a framework for recognizing animal sentience in a meaningful way would do well to embrace ASPP, BAR and ACT.

The third part of the "fiddling while Rome burns" objection is that, even if the first two parts are set aside, there remains the concern that my proposals target animal welfare, not animal liberation. Animal welfare, Marks argues, "serves animal industries as a convenient sop to citizen and consumer conscience." This point echoes several of the commentaries on Ng's (2016) recent article (Bekoff and Pierce 2016; Clark 2016; Leadbeater 2016; Marino 2016; Marks 2016). I don't think I can convince this particular kind of animal welfare sceptic, but I do not aim to do so. My aim is to combat a different kind of sceptic: one who maintains 
that fish or invertebrates could not possibly be sentient, and so could not possibly be deserving of even the basic protections we extend to mammals and birds. This is not to presuppose that existing protections for mammals and birds are adequate: only to presuppose that some protection is better than none.

\section{Review of the amended framework (v1.1)}

I will close with a brief review of my amended proposals and an invitation for further commentary. As before, the framework consists of an overarching principle or "meta-norm" (ASPP), an evidential bar (BAR) and a policy response (ACT). I have left ASPP unchanged. BAR incorporates the change suggested by C. Brown (Section 2.3), and ACT incorporates changes in light of commentaries by C. Brown, Mallatt, Woodruff, and Paez (Sections 1.1 and 5).

\section{ASPP:}

Where there are threats of serious, negative animal welfare outcomes, a lack of full scientific certainty as to the sentience of the animals in question shall not be used as a reason for postponing cost-effective measures to prevent those outcomes.

\section{BAR:}

(a) For the purposes of formulating animal protection legislation, there is sufficient evidence that animals of a particular order $\left(\mathrm{O}_{1}\right)$ are sentient if there is statistically significant evidence, obtained by experiments that meet normal scientific standards, of the presence of at least one credible indicator of sentience in at least one species of that order.

(b) If sufficient evidence by the lights of condition (a) has been obtained for two orders $\mathrm{O}_{1}$ and $\mathrm{O}_{2}$, and if normal methods of phylogenetic inference indicate that, conditional on the presence of sentience in orders $\mathrm{O}_{1}$ and $\mathrm{O}_{2}$, animals of a third order $\mathrm{O}_{3}$ are also likely to be sentient, then there is sufficient evidence that animals of the order $\mathrm{O}_{3}$ are sentient.

ACT:

(a) The scope of animal protection legislation should include all orders of animals for which the evidence of sentience is sufficient, according to the standard of sufficiency outlined in BAR.

(b) When an order of animals is included in the scope of animal protection legislation, costeffective measures to safeguard the welfare of these animals should be included in any legislation relevant to their treatment in any domain of human activity, including food production, scientific research, conservation work and recreational pursuits.

(c) In cases in which it is disputed whether an order $\mathrm{O}_{1}$ satisfies BAR, or in which there is experimental evidence of one credible indicator of sentience in $\mathrm{O}_{1}$ but not evidence of two, it may be appropriate to commission further research into the question of sentience in $\mathrm{O}_{1}$ as a matter of high funding priority, and to commit to review the status of $\mathrm{O}_{1}$ after a short period of time. If no significant new evidence comes to light either for or against sentience, there should be a presumption in favour of protecting $\mathrm{O}_{1}$.

I welcome further commentary on any aspect of these proposals, including (i) the list of credible indicators; (ii) the most appropriate taxonomic grain of analysis; and (iii) the application of the framework to particular taxa. 


\section{Acknowledgements}

Thanks again to all the commentators. This work was supported by a Philip Leverhulme Prize from the Leverhulme Trust.

\section{References}

Adamo, S. (2017) The "precautionary principle" - A work in progress. Animal Sentience $16(4)$.

Adamo, S. A. (2016) Do insects feel pain? A question at the intersection of animal behaviour, philosophy and robotics. Animal Behaviour 118: 75-79.

Ames, H., Mingolla, E., Sohail, A., Chandler, B., Gorchetchnikov, A., Léveillé, J., Livitz, G. and Versace, M. (2012) The animat: New frontiers in whole-brain modelling. IEEE Pulse 3(1): 47-50.

Animal Health and Animal Welfare Panel of the European Food Standards Agency [AHAW]. (2005) Aspects of the biology and welfare of animals used for experimental and other scientific purposes (EFSA-Q-2004-105). Annex to the EFSA Journal 292: 1-136.

Appel, M. and Elwood, R. W. (2009) Motivational trade-offs and potential pain experience in hermit crabs. Applied Animal Behaviour Science 119: 120-124.

Barr, S. and Elwood, R. W. (2011). No evidence of morphine analgesia to noxious shock in the shore crab, Carcinus maenas. Behavioral Processes 86: 340-344.

Barr, S., Laming, P. R., Dick, J. T. A. and Elwood, R. W. (2008) Nociception or pain in a decapod crustacean? Animal Behaviour 75: 745-751.

Basl, J. (2013) The ethics of creating artificial consciousness. APA Newsletter on Philosophy and Computers 13(1): 23-29.

Bekoff, M. and Pierce, J. (2016) Animal welfare cannot adequately protect nonhuman animals: The need for a science of animal well-being. Animal Sentience 7(2).

Benjamin, D. J. and 71 others. (2017) Redefine statistical significance. Nature Human Behaviour. doi.org/10.1038/s41562-017-0189-z

Benton, M. J. (2000) Stems, nodes, crown clades, and rank-free lists: Is Linnaeus dead? Biological Reviews 75: 633-648.

Bergamo, P., Maldonado, H. and Miralto, A. (1992). Opiate effect on the threat display in the crab Carcinus mediterraneus. Pharmacology Biochemistry and Behavior 42: 323-326.

Birch, J. (2017a) Animal sentience and the precautionary principle. Animal Sentience 16(1).

Birch, J. (2017b) Crabs and lobsters deserve protection from being cooked alive. Aeon, 3 November 2017.

Birch, J. (forthcoming) Animal cognition and human values. Philosophy of Science.

Bostrom, N. (2014) Superintelligence: Paths, Dangers, Strategies. Oxford: Oxford University Press.

Bostrom, N., and Yudkowsky, E. (2014). The ethics of artificial intelligence. In Frankish, K. and Ramsey, W. M. (Eds.), The Cambridge Handbook of Artificial Intelligence. Cambridge: Cambridge University Press, pp. 316-334.

Brown, C. (2017) A risk assessment and phylogenetic approach. Animal Sentience 16(3). Brown, R. (2017) Not statistically significant, but still scientific. Animal Sentience 16(14). Carder, G. (2017) A preliminary investigation into the welfare of lobsters in the UK. Animal Sentience 16(19). 
Clark, S. R. (2016) Slavery, welfare and the sixth extinction. Animal Sentience 7(13).

De Queiroz, K. and Gauthier, J. (1992) Phylogenetic taxonomy. Annual Review of Ecology and Systematics 23: 449-480.

Dupré, J. (1981) Natural kinds and biological taxa. Philosophical Review 90: 66-90.

Kitcher, P. (1984) Species. Philosophy of Science 51: 308-333.

Klein, C. (2017) Precaution, proportionality and proper commitments. Animal Sentience 16(9).

Mishler, B. D. (1999) Getting rid of species? In R. Wilson (Ed.), Species: New interdisciplinary Essays. MIT Press, pp. 307-315.

Elwood, R. W. (2012) Evidence for pain in decapod crustaceans. Animal Welfare 21(S2): 2327.

Elwood, R. W. and Appel, M. (2009) Pain experience in hermit crabs. Animal Behaviour 77:

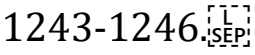

European Union. (2007) Treaty of Lisbon amending the Treaty on European Union and the Treaty establishing the European Community, signed at Lisbon, 13 December.

European Union. (2010) Directive 2010/63/EU of the European Parliament and of the Council on the protection of animals used for scientific purposes, 22 September.

Feinberg, T. E. and Mallatt, J. M. (2016). The Ancient Origins of Consciousness: How the Brain Created Experience. Cambridge, MA: MIT Press.

Gove, M. (2017) Animal Welfare: Written statement - HCWS267, 23 November.

Harnad, S. (2016) My orgasms cannot be traded off against others' agony. Animal Sentience $7(18)$.

Irvine, L. (2017) Animal pain and the social role of science. Animal Sentience 16(18).

Jennings, H. S. (1902) Studies on reactions to stimuli in unicellular organisms. IX. On the behavior of fixed Infusoria (Stentor and Vorticella), with special reference to the modifiability of Protozoon reactions. American Journal of Physiology 8: 23-60.

Jennings, H. S. (1906) Behavior of the Lower Organisms. New York: Columbia University Press.

Jones, R. C. (2017) The precautionary principle: A cautionary note. Animal Sentience 16(15).

Klein, C. and Barron, A. B. (2016) Insects have the capacity for subjective experience. Animal Sentience $9(1)$.

Leadbeater, S. (2017) Will the precautionary principle broaden acceptance of animal sentience? Animal Sentience 16(16).

Leadbeater, S. R. B. (2016) Animal suffering calls for more than a bigger cage. Animal Sentience 7(4).

Lozada, M., Romano, A. and Maldonado, H. (1988) Effect of morphine and naloxone on a defensive response of the crab Chasmagnathus granulatus. Pharmacology Biochemistry and Behavior 30: 635-640: [is

Magee, B. and Elwood, R. W. (2013) Shock avoidance by discrimination learning in the shore crab (Carcinus maenas) is consistent with a key criterion for pain. Journal of

Experimental Biology 216: 353-358.

Mallatt, J. (2017) Shoring up the precautionary BAR. Animal Sentience 16(7).

Marino, L. (2016) Why animal welfarism continues to fail. Animal Sentience 7(5).

Marks, J. (2016) End-state welfarism. Animal Sentience 7(6).

Mather, J. (2017) Support for the precautionary principle. Animal Sentience 16(10).

Mayr, E. (1961) Cause and effect in biology. Science 134(3489): 1501-1506. 
Mood, A. (2010) Worse things happen at sea: The welfare of wild-caught fish. fishcount.org.uk.

Ng, Y-K. (2016) How welfare biology and commonsense may help to reduce animal suffering. Animal Sentience 7(1).

Ng, Y-K. (2017) Justifying the precautionary principle with expected net-welfare maximization. Animal Sentience 16(12).

Paez, E. (2017) What harmful practices? The material scope of animal protection legislation. Animal Sentience 16(17).

Reber, A. S. (2017) What if all animals are sentient? Animal Sentience 16(6).

Rollins, B. (2017) Raising the moral consciousness of science. Animal Sentience 16(8).

Roth, B. and Grismbø, E. (2016) Electrical stunning of edible crabs (Cancer pagurus): From single experiments to commercial practice. Animal Welfare 25: 489-497.

Smith, J. A. and Boyd, K. M. (Eds.). (1991). Lives in the Balance: The Ethics of Using Animals in Biomedical Research. Oxford: Oxford University Press.

Stauffer, J. R., Jr. (2017) Cautions about precautions. Animal Sentience 16(2).

Steel, D. (2013) The precautionary principle and the dilemma objection. Ethics, Policy and Environment 16: 321-340:

Steel, D. (2014) Philosophy and the Precautionary Principle: Science, Evidence, and Environmental Policy. Cambridge: Cambridge University Press.s.

Sunstein, C. R. (2005) Laws of Fear: Beyond the Precautionary Principle. Cambridge: Cambridge University Press.

Tartar, V. (1961) The Biology of Stentor. Oxford: Pergamon Press.

Trewavas, A. (2014) Plant Behaviour and Intelligence. Oxford: Oxford University Press. United Nations. (1992) Rio Declaration on Environment and Development. Report of the United Nations Conference on Environment and Development, Rio de Janeiro, June 3-14. New York: United Nations.

Woodruff, M. L. (2017) Scientific uncertainty and the animal sentience precautionary principle. Animal Sentience 16(11). 


\section{UQÀM/ISC Cognitive Science Summer School June 26 - July 6 2018, Montreal, Canada}

\section{The Other Minds Problem: Animal Sentience and Cognition}

Overview. Since Descartes, philosophers know there is no way to know for sure what - or whether - others feel (not even if they tell you). Science, however, is not about certainty but about probability and evidence. The 7.5 billion individual members of the human species can tell us what they are feeling. But there are 9 million other species on the planet (20 quintillion individuals), from elephants to jellyfish, with which humans share biological and cognitive ancestry, but not one other species can speak: Which of them can feel - and what do they feel? Their human spokespersons - the comparative psychologists, ethologists, evolutionists, and cognitive neurobiologists who are the world's leading experts in "mind-reading" other species -- will provide a sweeping panorama of what it feels like to be an elephant, ape, whale, cow, pig, dog, bat, chicken, fish, lizard, lobster, snail: This growing body of facts about nonhuman sentience has profound implications not only for our understanding of human cognition, but for our treatment of other sentient species.

\begin{tabular}{|c|}
\hline $\begin{array}{l}\text { Gregory Berns: Decoding the Dog's Mind with Awake } \\
\text { Neuroimaging }\end{array}$ \\
\hline Gordon Burghardt: Probing the Umwelt of Reptiles \\
\hline $\begin{array}{l}\text { Jon Sakata: Audience Effects on Communication } \\
\text { Signals }\end{array}$ \\
\hline PANEL 1: Reptiles, Birds and Mammals \\
\hline $\begin{array}{l}\text { WORKSHOP 1: Kristin Andrews: The "Other" } \\
\text { Problems: Mind, Behavior, and Agency }\end{array}$ \\
\hline $\begin{array}{l}\text { Sarah Brosnan: How Do Primates Feel About Their } \\
\text { Social Partners? }\end{array}$ \\
\hline $\begin{array}{l}\text { Alexander Ophir: The Cognitive Ecology of } \\
\text { Monogamy }\end{array}$ \\
\hline $\begin{array}{l}\text { Michael Hendricks: Integrating Action and Perception } \\
\text { in a Small Nervous System }\end{array}$ \\
\hline PANEL 2: Primates, Voles and Worms \\
\hline $\begin{array}{l}\text { WORKSHOP 2: Jonathan Birch: Animal Sentience } \\
\text { and the Precautionary Principle }\end{array}$ \\
\hline $\begin{array}{l}\text { Malcolm Maclver: How Sentience Changed After Fish } \\
\text { Invaded Land } 385 \text { Million Years Ago }\end{array}$ \\
\hline $\begin{array}{l}\text { Sarah Woolley: Neural Mechanisms of Preference in } \\
\text { Female Songbird }\end{array}$ \\
\hline $\begin{array}{l}\text { Simon Reader: Animal Social Learning: Implications } \\
\text { for Understanding Others }\end{array}$ \\
\hline PANEL 3: Sea to Land to Air \\
\hline $\begin{array}{l}\text { WORKSHOP 3: Steven M. Wise: Nonhuman } \\
\text { Personhood }\end{array}$ \\
\hline $\begin{array}{l}\text { Tomoko Ohyama: Action Selection in a Small Brain } \\
\text { (Drosophila Maggot) }\end{array}$ \\
\hline $\begin{array}{l}\text { Mike Ryan: "Crazy Love": Nonlinearity and } \\
\text { Irrationality in Mate Choice }\end{array}$ \\
\hline $\begin{array}{l}\text { Louis Lefebvre: Animal Innovation: From Ecology to } \\
\text { Neurotransmitters }\end{array}$ \\
\hline $\begin{array}{l}\text { PANEL 4: Maggots, Frogs and Birds: Flexibility } \\
\text { Evolving }\end{array}$ \\
\hline SPECIAL EVENT: Mario Cyr: Polar Bears \\
\hline $\begin{array}{l}\text { Colin Chapman: Why Do We Want to Think People } \\
\text { Are Different? }\end{array}$ \\
\hline Vladimir Pradosudov: Chickadee Spatial Cognition \\
\hline Jonathan Balcombe: The Sentient World of Fishes \\
\hline PANEL 5: Like-Mindedness and Unlike-Mindedness \\
\hline $\begin{array}{l}\text { WORKSHOP } 5 \text { (part 1): Gary Comstock: A Cow's } \\
\text { Concept of Her Future }\end{array}$ \\
\hline
\end{tabular}

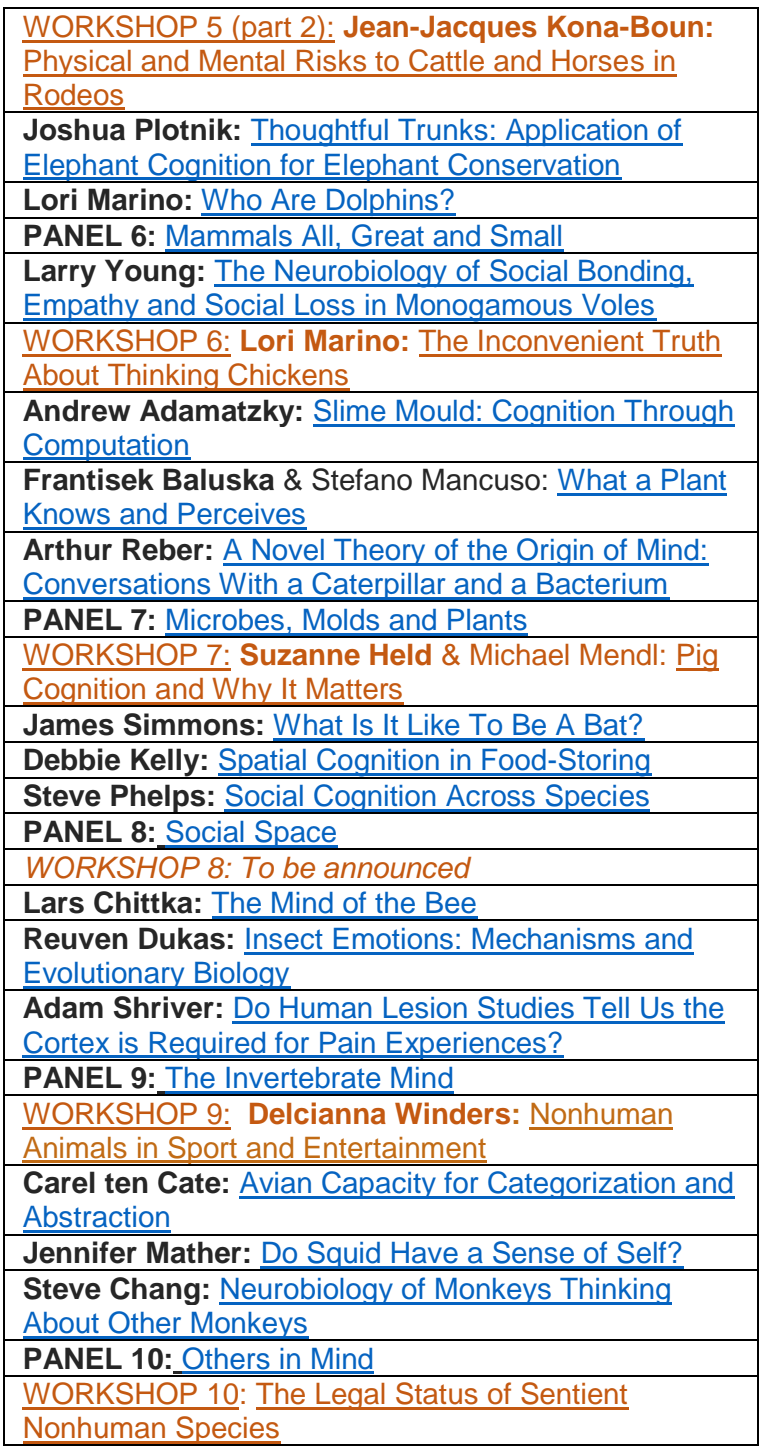

